\title{
Skin Response Date Time of Reference Timepoint
}

National Cancer Institute

\section{Source}

National Cancer Institute. Skin Response Date Time of Reference Timepoint. NCI

Thesaurus. Code C117698.

The date and time of a specific reference point for the skin reponse assessment. 